\title{
Production of soluble regulatory hydrogenase from Ralstonia eutropha in Escherichia coli using a fed-batch-based autoinduction system
}

\author{
Qin Fan, Peter Neubauer and Matthias Gimpel ${ }^{*}$ D
}

\begin{abstract}
Background: Autoinduction systems can regulate protein production in Escherichia coli without the need to monitor cell growth or add inducer at the proper time following culture growth. Compared to classical IPTG induction, autoinduction provides a simple and fast way to obtain high protein yields. In the present study, we report on the optimization process for the enhanced heterologous production of the Ralstonia eutropha regulatory hydrogenase (RH) in $E$. coli using autoinduction. These autoinduction methods were combined with the EnPresso B fed-batch like growth system, which applies slow in situ enzymatic glucose release from a polymer to control cell growth and protein synthesis rate.
\end{abstract}

Results: We were able to produce $125 \mathrm{mg} \mathrm{L}^{-1} \mathrm{RH}$ corresponding to a productivity averaged over the whole process time of $3 \mathrm{mg}(\mathrm{L} \mathrm{h})^{-1}$ in shake flasks using classic single-shot IPTG induction. IPTG autoinduction resulted in a comparable volumetric $\mathrm{RH}$ yield of $112 \mathrm{mg} \mathrm{L}^{-1}$ and due to the shorter overall process time in a 1.6-fold higher productivity of $5 \mathrm{mg}(\mathrm{L} \mathrm{h})^{-1}$. In contrast, lactose autoinduction increased the volumetric yield more than 2.5 -fold and the space time yield fourfold reaching $280 \mathrm{mg} \mathrm{L}^{-1}$ and $11.5 \mathrm{mg}(\mathrm{L} \mathrm{h})^{-1}$, respectively. Furthermore, repeated addition of booster increased $\mathrm{RH}$ production to $370 \mathrm{mg} \mathrm{L}^{-1}$, which to our knowledge is the highest $\mathrm{RH}$ concentration produced in E. coli to date.

Conclusions: The findings of this study confirm the general feasibility of the developed fed-batch based autoinduction system and provide an alternative to conventional induction systems for efficient recombinant protein production. We believe that the fed-batch based autoinduction system developed herein will favor the heterologous production of larger quantities of difficult-to-express complex enzymes to enable economical production of these kinds of proteins.

Keywords: Regulatory hydrogenase, Difficult-to-express protein, Ralstonia eutropha, Escherichia coli, IPTG autoinduction, Lactose autoinduction, Fed-batch like cultivation, EnPresso B

${ }^{*}$ Correspondence: matthias.gimpel@tu-berlin.de

Chair of Bioprocess Engineering, Technische Universität Berlin, Straße des

17. Juni 135, 10623 Berlin, Germany

\section{Background}

Recombinant protein production in Escherichia coli is most extensively performed under the control of lactose-inducible promoter systems [1]. Alternative to manual IPTG induction of gene expression from these $\mathrm{P}_{l a c}$-derived promoters, autoinduction is a simple method for induction of recombinant protein synthesis. 
Cultures can be simply inoculated into autoinducing medium and grown to saturation without the need to follow the growth of the culture and add the inducer at an appropriate time. This provides huge advantages in highthroughput applications and time scheduling of shakeflask experiments. Lactose can be used as the potent and cheap replacement of IPTG as inducer for recombinant protein synthesis [2-6]. In principle, the lac operon is induced when allolactose derived from lactose by the active intracellular $\beta$-galactosidase, binds and inactivates the LacI repressor, thereby as a consequence of lactose uptake into the cells [7]. Autoinduction is based on the glucose catabolite repression and inducer exclusion phenomenon which is initiated by the presence of glucose [8-11]. When carbon substrate mixtures of glucose, lactose or glycerol are used, glucose is preferentially consumed followed by glycerol and lactose that also acts as inducer of $\mathrm{P}_{\text {lac }}$ controlled genes [12]. Studier and colleagues have explored and optimized autoinduction media. They have been successfully applied for production of target proteins in small and large scale using T7 expression systems [5, 13-15]. Interestingly, these lactose autoinduction media provided higher cell densities and target protein yields compared to manual IPTG induction in commonly used media $[5,16,17]$. Unlike IPTG, lactose is taken up by the lacY-encoded lactose permease and metabolized to the actual inducer allolactose in $E$. coli, resulting in a delayed induction effect [7]. Moreover, the induction effect by lactose is highly sensitive to the glucose concentration as catabolite repression results in reduced lactose uptake rates at excess glucose $[7,18$, 19]. Furthermore, several defined autoinduction media including various amino acid and vitamin supplements have been successfully applied to label target proteins with isotopes or selenomethionine [5, 20-23]. Generally, glycerol as a growth-supporting carbon and energy source in lactose autoinduction media supports high cell density $[24,25]$. However, in such system, recombinant protein production is highly dependent on the oxygenation level, particularly reduced production at high aeration rates due to an altered order of carbon source preference from lactose to glycerol has been observed [12]. This strong oxygen-sensitivity of protein production complicates scalability and reproducibility of autoinduction cultures or restricts the protein yields at low oxygenation level due to lower cell densities [26, 27].

Recently, the use of a combination of lactose and glucose-limited EnPressoB fed-batch medium demonstrated that glucose limitation rather than glucose starvation is important for $E$. coli, consequently protein expression works well with a continuous biocatalytic glucose release from dextrins [28-31]. Unlike in glycerol-based autoinduction media, in EnPresso-based medium lactose only serves as inducer but is not catabolized as carbon source thereby reducing the oxygen sensitivity of lactose autoinduction [31, 32]. The slow glucose release does not prevent lactose autoinduction and the lactose concentration stays approximately constant at reasonable high cell densities $\left(\mathrm{OD}_{600}>20\right)$ during $24 \mathrm{~h}$ cultivation [32].

[NiFe]-hydrogenases are generally heterogeneous, multicomplex, metalloenzymes [33, 34]. According to their physiological function, composition and localization in the organism, [NiFe]-hydrogenases have so far been classified into five distinct groups, including membranebound uptake hydrogenases (MBH), cytoplasmic uptake hydrogenases and $\mathrm{H}_{2}$ sensors (cyanobacterial, $\mathrm{H}_{2}$-sensing hydrogenases), bidirectional hydrogenases containing additional subunits for binding soluble substrates $\left(\mathrm{NAD}^{+}\right.$ and/or $\mathrm{NADP}^{+}, \mathrm{MV}, \mathrm{F} 420$ ), membrane associated $\mathrm{H}_{2}$-evolving hydrogenases and high affinity $\mathrm{H}_{2}$-oxidizing hydrogenases [35, 36]. However, the functional core of the [NiFe]-hydrogenases is basically a heterodimeric protein with a large and a small subunit, although additional subunits are present in many of these enzymes [35, 37]. Interestingly, a few [NiFe]-hydrogenases are tolerant to $\mathrm{O}_{2}$ which is a prerequisite for their industrial application $[35,38,39]$. The $\mathrm{O}_{2}$-tolerant regulatory hydrogenase (RH) from Ralstonia eutropha H16 which is composed of the large subunit HoxC and the small subunit HoxB, together with the histidine kinase HoxJ they form the $\mathrm{H}_{2}$-sensing complex $(\operatorname{HoxBC})_{2} \mathrm{Hox}_{4}$ [40-42]. More recently, the single HoxBC heterodimer isolated from $R$. eutropha has been shown to maintain its catalytic activity and its tertiary structure similar to the classic hydrogenases and was widely used in a number of in vitro spectroscopic studies [41, 43-47]. From structural and functional points of view, RH is superior to other hydrogenases and considered as valuable and simplest model system for studying multicomplex hydrogenases.

We have recently reconstituted the synthesis of the RH subunits HoxBC from R. eutropha in E. coli BL21 Gold under control of a $\mathrm{P}_{\text {lac }}$-derived promoter [48]. Using classical IPTG induction soluble $\mathrm{RH}$ was produced in batch cultivations at a modest yield of $14 \mathrm{mg}$ $\mathrm{L}^{-1}$. When switching to EnPresso-based fed-batch like shake-flask cultures the yield was increased more than 18-fold to approx. $255 \mathrm{mg} \mathrm{L}^{-1}$ [48], corresponding to several 100-folds increase in the RH amount purified from R. eutropha [44]. In this study, we aimed to examine the general applicability of autoinduction in combination with the EnPresso B glucose release growth system and the potential advantages of such a combined approach for the improvement of recombinant protein production compared to the classical single-shot IPTG induction. Using screening experiments in deepwell plates we investigated optimal IPTG and lactose concentrations for 
autoinduced RH production under fed-batch like conditions. Compared to classical IPTG induction about twofold higher volumetric yields and even fourfold higher space-time yields were obtained with lactose autoinduction. Finally, the heterologous RH production in E. coli achieved using fed-batch based lactose autoinduction showed a good scalability in shake flask scales and can be applied to rationally designed bioreactor cultivations.

\section{Results \\ Effect of concentrations of glucose/lactose ratio on $\mathrm{RH}$ production in EnPresso B-based autoinduction}

Derivatives of the lac promoter are widely used in biotechnological processes for the controlled regulation of gene expression. Usually production of the recombinant protein is induced by a single shot addition of the artificial inducer IPTG at a certain point of the cultivation. In contrast, lactose-based autoinduction is a simple and rapid way to obtain high yields of a recombinant protein. In an autoinduction medium, the presence of glucose inhibits induction by lactose through catabolite repression and inducer exclusion [5]. To evaluate the suitability of autoinduction for heterologous production of the $R$. eutropha $\mathrm{RH}$, we used $E$. coli BL21-Gold derivative BQF8RH (E. coli BL21-Gold transformed with plasmid pQF8 carrying the RH structural genes hoxB and hox $C$ under control of the $\mathrm{P}_{\text {lac-CTU }}$ promoter) that allows IPTG-inducible RH gene expression [48]. Cultures were performed in 24-deepwell plates (3 $\mathrm{mL}$ working scale) containing non-boosted EnPresso B medium supplemented with different amounts of glucose $(0.5$ or $1 \mathrm{~g}$ $\mathrm{L}^{-1}$ ) and lactose $\left(0.5,1\right.$ or $\left.2 \mathrm{~g} \mathrm{~L}^{-1}\right)$. Similar cell growth of the $E$. coli strain was observed with all glucose and lactose combinations added (Fig. 1A). The highest cell density with $\mathrm{OD}_{600}$ of 12.5 was reached with addition of $1 \mathrm{~g}$ $\mathrm{L}^{-1}$ glucose and $2 \mathrm{~g} \mathrm{~L}^{-1}$ lactose (Fig. 1A). Thus, despite the addition of higher amounts of glucose and lactose, no noticeable effect on growth was observable. The specific production of HoxB was detected by Western blotting. As expected, no hydrogenase was produced without addition of lactose, while $\mathrm{HoxB}_{\text {Strep }}$ was detectable in all other samples (Fig. 1B), indicating that lactose based autoinduction is feasible for $\mathrm{RH}$ production in E. coli. The highest RH level was observed in EnPresso supplemented with $0.5 \mathrm{~g} \mathrm{~L}^{-1}$ glucose and $2 \mathrm{~g} \mathrm{~L}^{-1}$ lactose.

\section{Screening of lactose concentrations for autoinduction of $\mathrm{RH}$ production}

To further investigate the role of lactose autoinduction we compared $\mathrm{RH}$ production induced by different concentrations of lactose $\left(0.5,2\right.$ or $\left.4 \mathrm{~g} \mathrm{~L}^{-1}\right)$ during growth in boosted and non-boosted EnPresso as above. Again $0.5 \mathrm{~g} \mathrm{~L}^{-1}$ glucose was added to the cultivations to

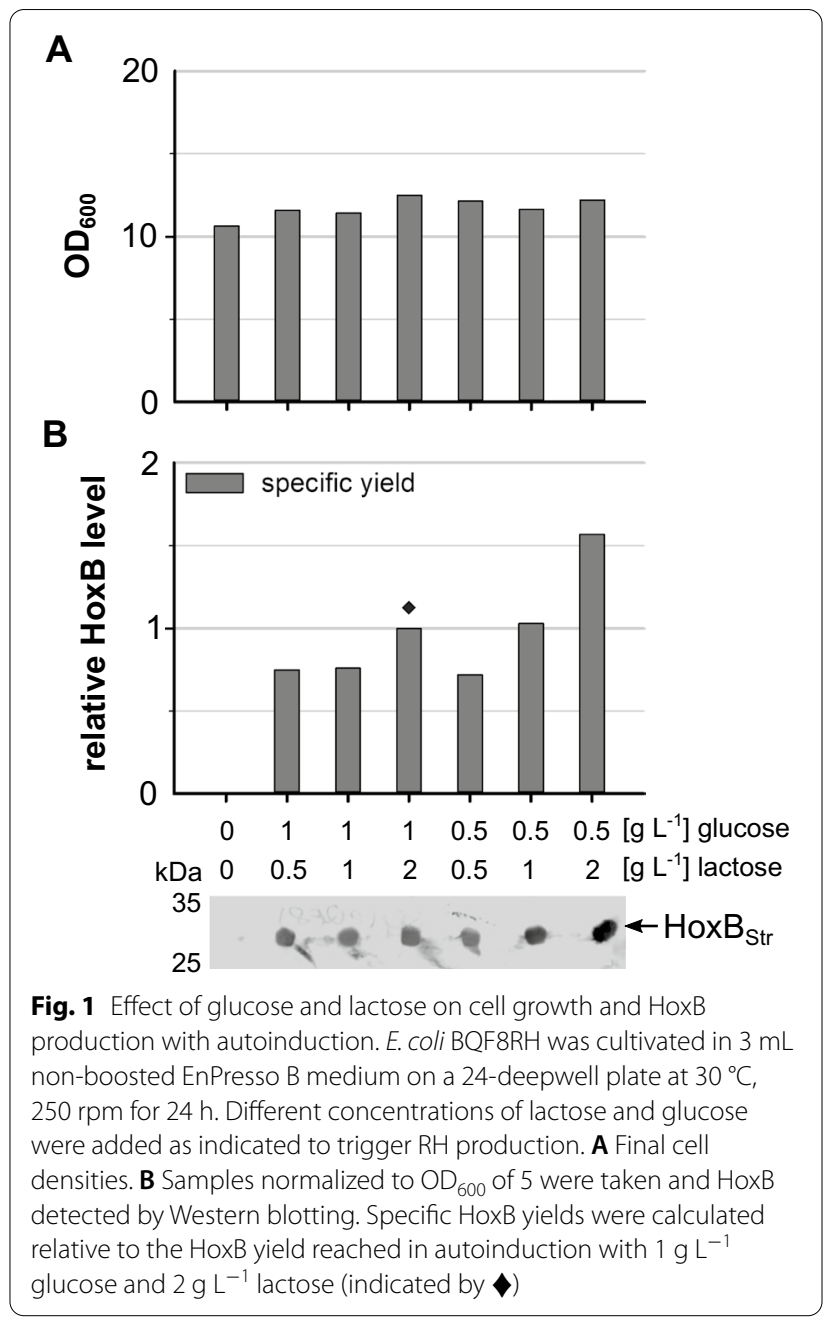

inhibit protein expression at the beginning. As expected, the boosted cultures reached final $\mathrm{OD}_{600} \mathrm{~s}$ of approx. 45 after $30 \mathrm{~h}$ which is about threefold higher compared to the non-boosted cultures (Fig. 2A). At indicated time points samples normalized to $\mathrm{OD}_{600}$ of 5 were taken and HoxB $_{\text {Strep }}$ production analysed by Western blotting with Strep-tag specific antibodies. The specific HoxB level steadily increased over the cultivation time in all cultures indicating that lactose based autoinduction of $\mathrm{RH}$ expression is feasible (Fig. 2B, C). In both boosted and non-boosted cultures, approx. $80 \%$ of the maximum specific RH level was already reached after $6 \mathrm{~h}$ with all inducer concentrations tested. Interestingly, HoxB was already detectable within $2 \mathrm{~h}$ of cultivation, indicating that the initial glucose concentration $\left(0.5 \mathrm{~g} \mathrm{~L}^{-1}\right)$ is low enough to allow lactose to trigger $\mathrm{RH}$ production during the early stage of cultivation. Furthermore, our results show that $2 \mathrm{~g} \mathrm{~L}^{-1}$ lactose is optimal for autoinduction, as this resulted in a slightly higher $\mathrm{RH}$ level relative to 0.5 or $4 \mathrm{~g} \mathrm{~L}^{-1}$ lactose. In addition, cultures with booster 


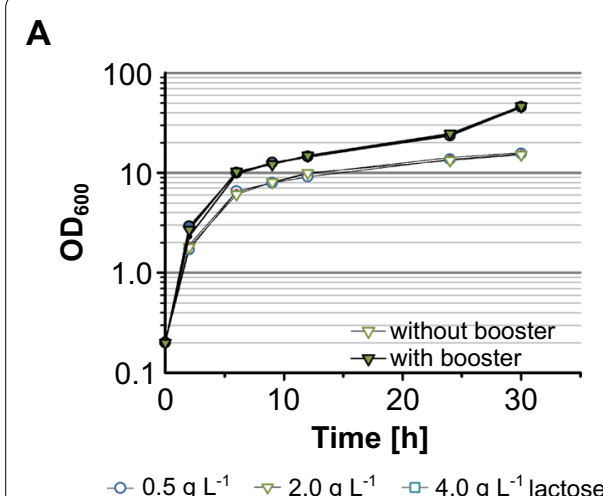

B

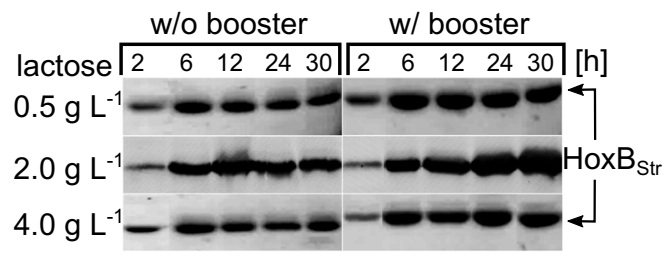

C
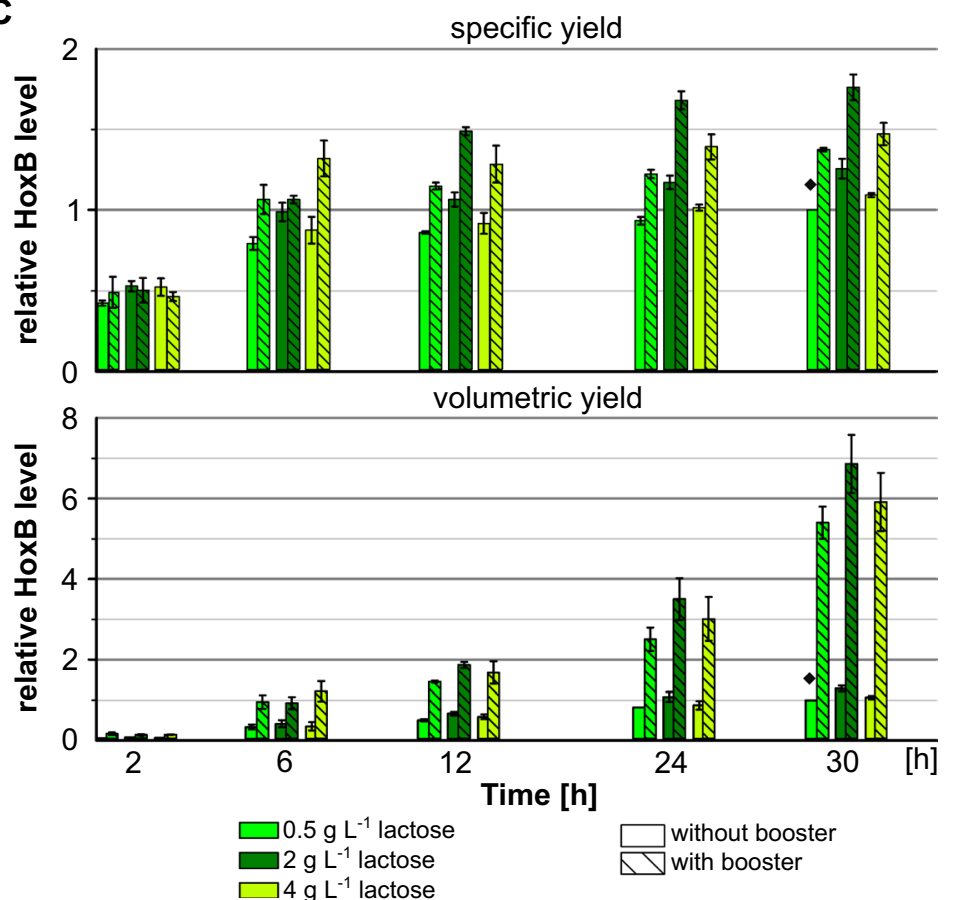

Fig. 2 RH production with autoinduction by varying concentrations of lactose. E. coli BQF8RH was cultivated in $3 \mathrm{~mL}$ EnPresso B medium with/out booster on 24-deepwell plate at $30^{\circ} \mathrm{C}, 250 \mathrm{rpm}$ for $30 \mathrm{~h}$. Autoinduction was achieved by addition of different lactose concentrations as indicated and $0.5 \mathrm{~g} \mathrm{~L}^{-1}$ glucose. Samples normalized to $\mathrm{OD}_{600}$ of 5 were taken at the indicated time points and used for detection of HoxB levels by Western blotting (WB) A growth curve, B WB for detection of HoxB yields, C specific HoxB yield (top) and volumetric HoxB yield (bottom). Both specific and volumetric yield were calculated relative to the HoxB yield reached after $30 \mathrm{~h}$ in non-boosted EnPresso induced with $0.5 \mathrm{~g} \mathrm{~L}^{-1}$ lactose (indicated by $\diamond)$

added from the beginning of the cultivation show a 1.4fold higher specific RH level compared to non-boosted cultures (Fig. 2B, C) which is in good agreement with the previously observed positive effect of the booster [48]. Nevertheless, due to the higher cell density addition of booster resulted in a 4.5-fold higher final volumetric HoxB yield.

\section{Screening of IPTG concentrations for autoinduction of RH production}

The conventional induction protocol for gene expression using $\mathrm{P}_{\text {lac }}$ derivatives is the single shot IPTG induction which is commonly performed after reaching a certain cell density. Recently, we have demonstrated that the single shot IPTG induction of the EnPresso B cultures with IPTG concentrations between 50 and $1000 \mu \mathrm{M}$ provided fairly similar yields of recombinant $\mathrm{RH}$ protein whilst low IPTG concentrations proofed beneficial for the solubility of the recombinant protein [48]. To investigate the effect of IPTG autoinduction in EnPresse B medium on cell growth and RH production, we compared RH expression induced by different concentrations of IPTG $(0,10$, $20,50,80$ or $150 \mu \mathrm{M})$ performed in 24-deepwell plates.
Analogous to autoinduction with lactose, $0.5 \mathrm{~g} \mathrm{~L}^{-1}$ glucose was supplied to the media to inhibit the IPTG uptake and subsequent hox gene expression at the beginning of the cultivation. As before, addition of booster facilitated cell growth and resulted in final $\mathrm{OD}_{600} \mathrm{~s}$ above 40 which is threefold higher compared to the non-boosted cultures (Fig. 3A).

However, interestingly the strength of induction did not influence the growth neither boosted and nor for nonboosted cultures (Fig. 3A). HoxB was already detectable after $2 \mathrm{~h}$ of cultivation and the specific HoxB level steadily increased until $24 \mathrm{~h}$ of cultivation independent from booster and inducer concentration (Fig. 3C). Compared to induction with 10 or $150 \mu \mathrm{M}$ IPTG, slightly higher $\mathrm{RH}$ titers were obtained by induction with $50 \mu \mathrm{M}$ IPTG. Regardless of the inducer concentration, boosted cultures showed an approx. 1.5-fold higher HoxB level, which is in good accordance with previous results [48]. Again, the higher cell densities in boosted cultures resulted in about 5 to 6 -fold higher volumetric yields compared to nonboosted cultures.

In summary, all cultures demonstrated a seemingly stable $\mathrm{RH}$ expression profile and steady $\mathrm{RH}$ accumulation 

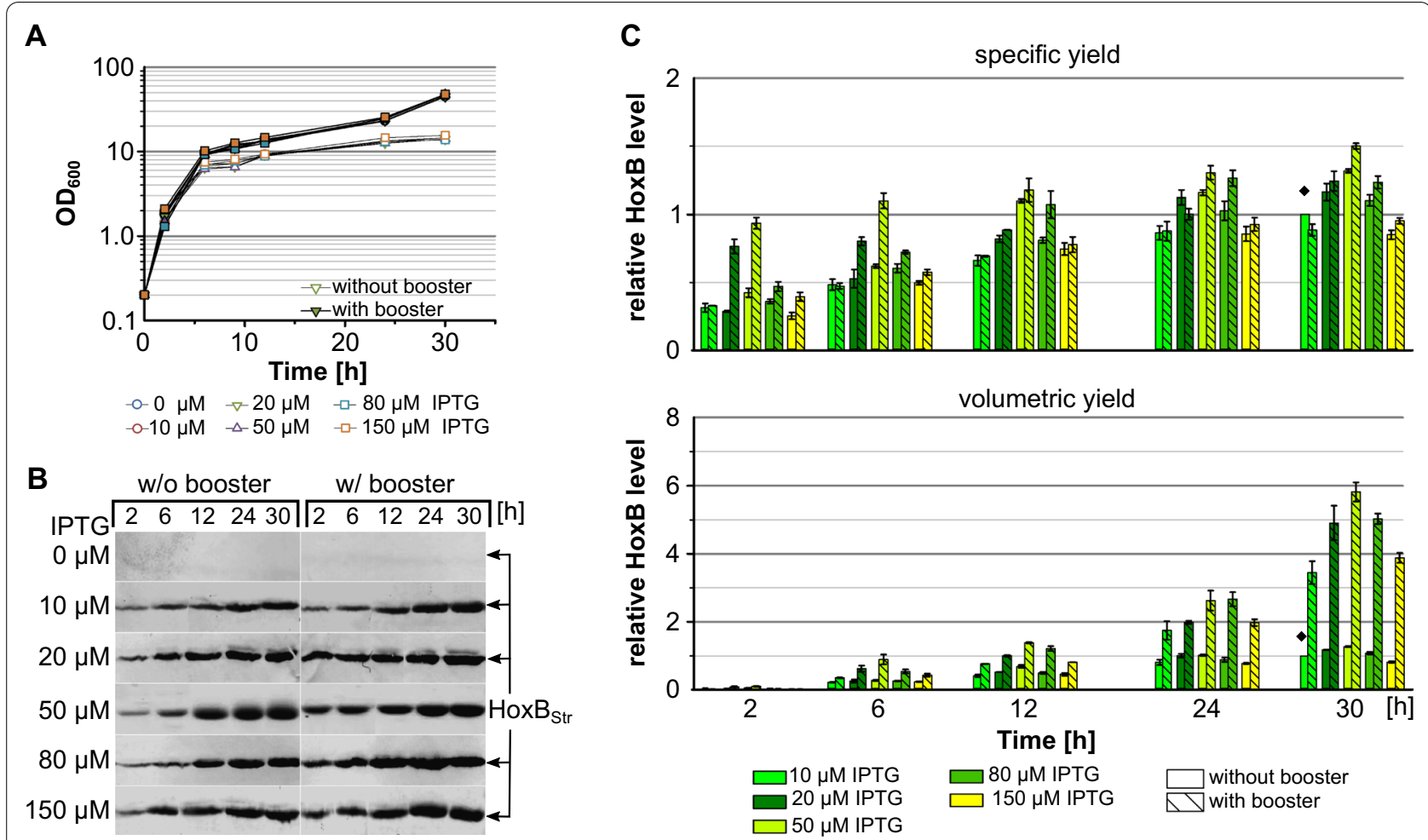

Fig. $3 \mathrm{RH}$ production with autoinduction by varying concentrations of IPTG. E. coli BQF8RH was cultivated in $3 \mathrm{~mL}$ EnPresso B medium with/out booster on 24-deepwell plate at $30^{\circ} \mathrm{C}, 250 \mathrm{rpm}$ for $30 \mathrm{~h}$. Autoinduction was achieved by addition of different IPTG concentrations as indicated and $0.5 \mathrm{~g} \mathrm{~L}^{-1}$ glucose. Samples normalized to $\mathrm{OD}_{600}$ of 5 were taken at the indicated time points and used for detection of HoxB levels by Western blotting (WB). A Growth curve, B WB for detection of HoxB yields, C specific HoxB (top) and volumetric HoxB yield (bottom). Both specific and volumetric yield were calculated relative to the HoxB yield reached after $30 \mathrm{~h}$ in non-boosted EnPresso induced with $0.5 \mathrm{~g} \mathrm{~L}^{-1}$ lactose (indicated by 今)

during the whole cultivations. Here, the optimal concentrations for autoinduction seem to be $50 \mu \mathrm{M}$ IPTG and $2 \mathrm{~g} \mathrm{~L}^{-1}$ lactose, respectively. Thus, autoinduction with lactose or IPTG can be used for recombinant RH production in fed-batch like EnPresso cultures.

\section{Effect of glucose polymer feeding on RH production}

Addition of glucose polymer to boost the EnPresso fedbatch like cultures improved final cell density and $\mathrm{RH}$ productivity in both classical IPTG induction [48] and autoinduction (see above). To further investigate the effect of the booster on $\mathrm{RH}$ production, we performed cultivation of E. coli BQF8RH in 24-DWPs with addition of different booster amounts. In all cases $\mathrm{RH}$ production was induced by either lactose or IPTG autoinduction. As expected, increasing amounts of booster gradually increased cell growth (Fig. 4A; Additional file 1: Fig. S1). Thus, this underlines the obvious influence of boosting concentrations on cell growth. Similarly, analysis of final RH levels using Western blotting (Fig. 4B) corroborates that $\mathrm{RH}$ production is positively affected by increased booster amounts. However, the highest specific yield is reached with $1 \times$ booster and addition of $2 \times$ booster did not significantly increase the specific $\mathrm{RH}$ yield further (Fig. 4C). Nevertheless, a slight increase in cell density with $2 \times$ booster resulted in a slightly higher volumetric $\mathrm{RH}$ yield compared to the $1 \times$ boosting. The same booster effect could be observed for both IPTG and lactose autoinduction. Moreover, comparable specific RH levels were observed independent from the autoinducer (Fig. 4B). Hence, lactose autoinduction according to the higher cell density (Fig. 4C) resulted in higher RH production titers which is consistent with the results described above.

\section{$\mathrm{RH}$ production with IPTG/lactose autoinduction in shake flasks}

After initial screening trials in 24-deepwell plates the cultures were scaled up to a broth volume of $50 \mathrm{~mL}$ cultivated in $250 \mathrm{~mL}$ Ultra Yield shake flasks as described in "Materials and methods". Protein production was induced for $24 \mathrm{~h}$ with $50 \mu \mathrm{M}$ IPTG or $2 \mathrm{~g} \mathrm{~L}^{-1}$ lactose which were added into the medium together with $0.5 \mathrm{~g} \mathrm{~L}^{-1}$ glucose at the beginning of the cultivations. $\mathrm{RH}$ was purified by affinity chromatography and analysed by SDS-PAGE. 

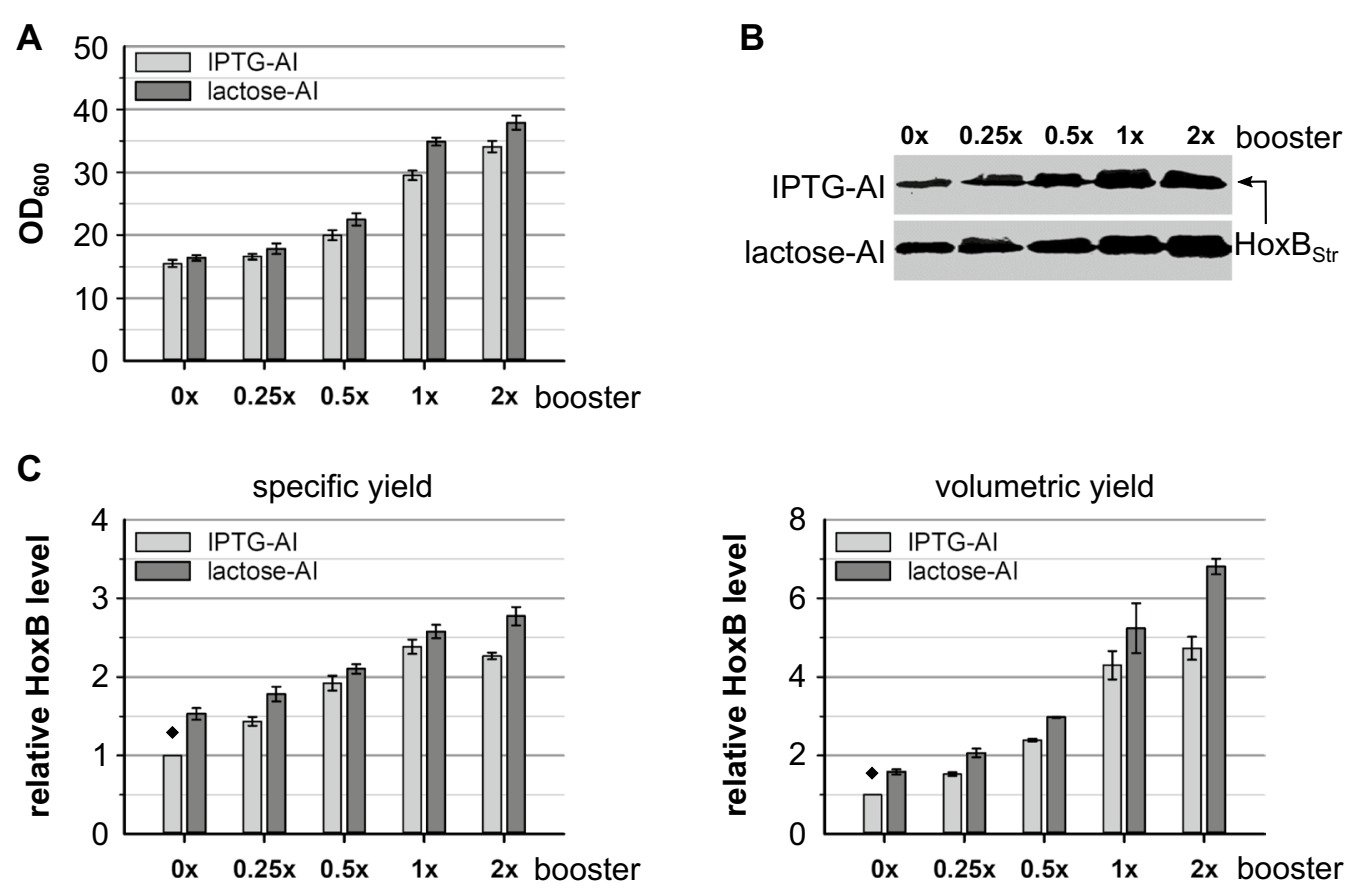

Fig. 4 Effect of glucose polymer boosting on cell growth and RH production. E. coli BQF8RH was cultivated in $3 \mathrm{~mL}$ EnPresso B medium with varying booster concentrations $(0 \times, 0.25 \times, 0.5 \times, 1 \times, 2 \times)$ on 24-deepwell plate at $30^{\circ} \mathrm{C}, 250 \mathrm{rpm}$ for $30 \mathrm{~h}$. $\mathrm{RH}$ expression was autoinduced by $50 \mu \mathrm{M}$ IPTG or $2 \mathrm{~g} \mathrm{~L}^{-1}$ lactose in the presence of $0.5 \mathrm{~g} \mathrm{~L}^{-1}$ glucose. Samples normalized to $\mathrm{OD}_{600}$ of 5 were taken at the end of cultivation and used for detection of HoxB levels by Western blotting (WB). A Cell growth, B WB for detection of HoxB yields, C specific HoxB yield and volumetric HoxB yield. Both specific and volumetric yield were calculated relative to the HoxB yield reached in $0 \times$ boosted IPTG-autoinduced EnPresso culture (indicated by

While the final $\mathrm{OD}_{600} \mathrm{~s}$ after $24 \mathrm{~h}$ induction did not differ significantly between IPTG and lactose autoinduction cultures, compared to single shot induction with IPTG the final $\mathrm{OD}_{600}$ was about 1.5-fold lower (Fig. 5A). This is probably attributed to the significantly longer cultivation time when performing single shot induction, since induction is carried out after $18 \mathrm{~h}$ by which time the cultures have already reached an $\mathrm{OD}_{600}$ of about 10 . Compared to classical single shot induction with IPTG, slightly lower volumetric yields were achieved with IPTG autoinduction, whereas specific yields were slightly higher (Fig. 5B). As a consequence of the shorter total process duration when using IPTG autoinduction, the space-time yield could be elevated about 1.6-fold.

By using $2 \mathrm{~g} \mathrm{~L}^{-1}$ lactose for autoinduction, the results of IPTG autoinduction could be significantly exceeded. Furthermore, higher volumetric yields were obtained both in EnPresso cultures with and without booster using lactose autoinduction compared to classical IPTG induction. In particular, in boosted EnPresso cultures, a final $\mathrm{RH}$ production titre of $278 \mathrm{mg} \mathrm{L}^{-1}$ could be achieved. The positive effect of lactose autoinduction on $\mathrm{RH}$ production is also reflected in the specific yield and the space-time yield of approx. $11.5 \mathrm{mg}(\mathrm{L} \mathrm{h})^{-1}$ in connection with the shorter process time, corresponding to fourfold increase compared to standard IPTG induction. As expected, for lactose and IPTG based autoinduction, booster addition improved the final volumetric and specific $\mathrm{RH}$ production by approximately 2 - and 3 -fold, respectively, compared to without booster. Therefore, it can be assumed that autoinduction provides an alternative way to enhance recombinant $\mathrm{RH}$ production yields.

\section{Enhanced RH production by repeated glucose polymer feeding}

The continued glucose release by supply of additional polymer booster to the medium had a positive effect on cell growth and RH production as described above. Thus, we attempted to improve the $\mathrm{RH}$ production by repeated continued glucose supply. Parallel cultivations in shake flasks were carried out based on classic singleshot IPTG induction with $50 \mu \mathrm{M}$ IPTG and lactose autoinduction using $2 \mathrm{~g} \mathrm{~L}^{-1}$ lactose (Fig. 6). The 1st dose of booster and biocatalyst was added at the induction point and a 2nd dose of booster and biocatalyst $\left(4.5 \mathrm{U} \mathrm{L}^{-1}\right.$ for IPTG induction, $3 \mathrm{U} \mathrm{L}^{-1}$ for lactose-autoinduction) was added after $12 \mathrm{~h}$ of induction. Without glucose polymer feeding, cells reached a final $\mathrm{OD}_{600}$ of $18-21$ after $36 \mathrm{~h}$ of 

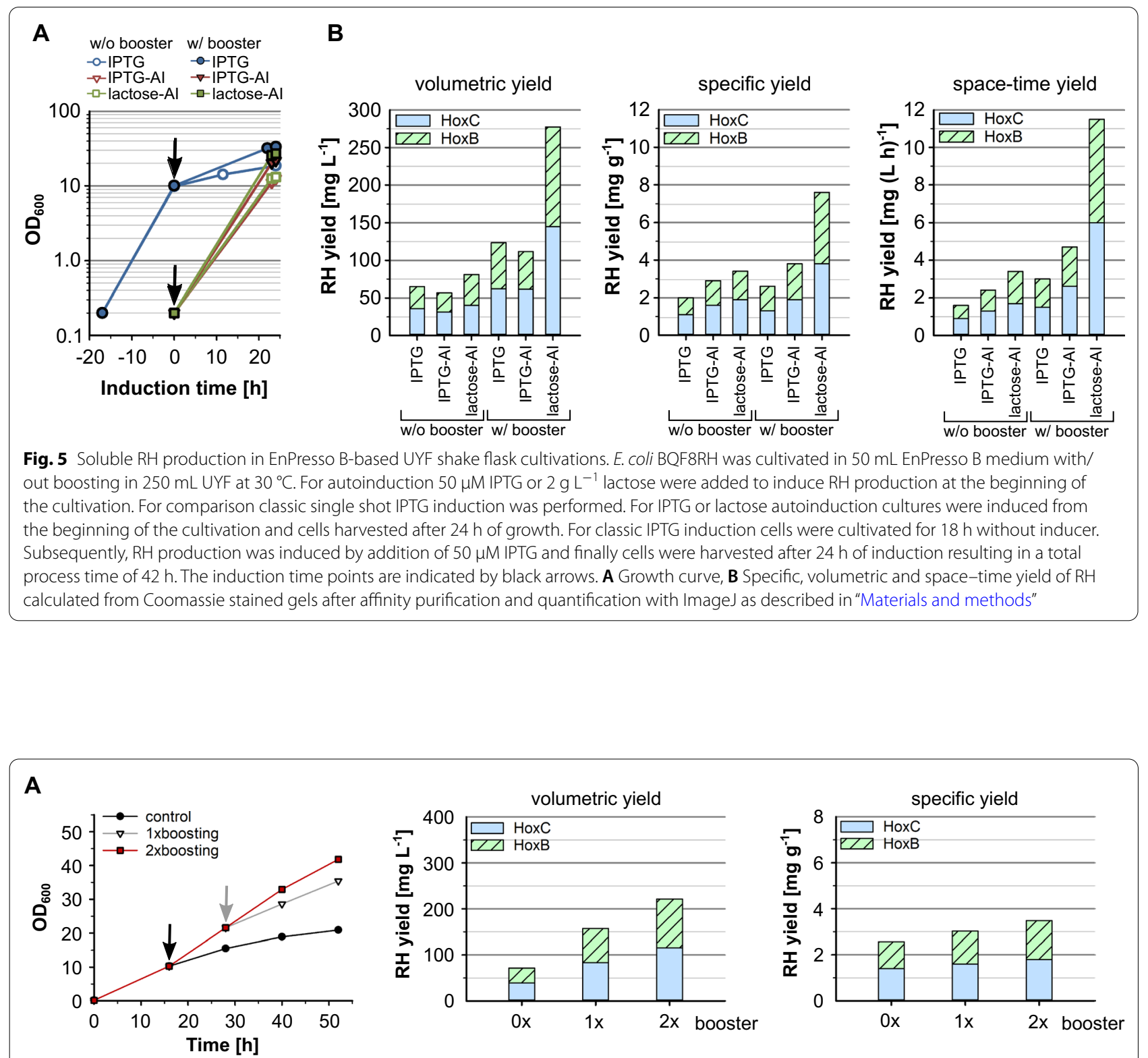

B
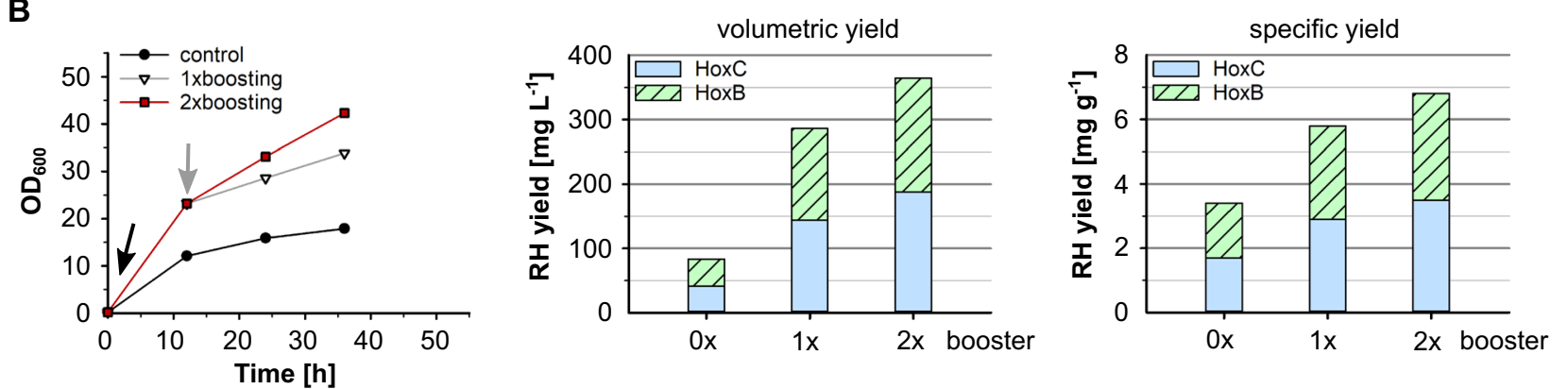

Fig. 6 Glucose polymer boosting for soluble RH production. E. coli BQF8RH was cultivated in $50 \mathrm{~mL}$ EnPresso B medium with/without boosting in $250 \mathrm{~mL}$ UYF at $30^{\circ} \mathrm{C}$. Growth curves, specific and volumetric RH yield are presented. The RH yields were calculated from Coomassie stained gels after affinity purification and quantification with ImageJ as described in "Materials and methods". A RH production using classic single-shot IPTG induction. B RH production using lactose-autoinduction. Black arrow: addition of booster and induction point; Grey arrow: addition of a second dose of booster 
induction with IPTG or lactose, respectively. With glucose polymer feeding, the final cell density was remarkably increased in both cultivations up to an $\mathrm{OD}_{600}$ of 35 with single polymer feeding and even approx. 42 with repeated, two-times glucose polymer feeding. As before the addition of booster resulted not only in an increased biomass production but also in a higher specific $\mathrm{RH}$ yield. Consequently, the volumetric $\mathrm{RH}$ yield obtained with lactose autoinduction increased to $366 \mathrm{mg} \mathrm{L}^{-1}$. Overall, a nearly twofold increase in specific $\mathrm{RH}$ yields could be obtained with lactose autoinduction compared to IPTG induction with a maximum of $7 \mathrm{mg} \mathrm{g}^{-1}$ using lactose autoinduction with two-times glucose polymer feeding.

\section{Scalability of the $\mathrm{RH}$ production}

To further evaluate the use of lactose autoinduction for $\mathrm{RH}$ production, cell densities and final $\mathrm{RH}$ yields obtained in deepwell plate and in $125 \mathrm{~mL}$ or $250 \mathrm{~mL}$ shake flask cultures were compared after $24 \mathrm{~h}$ of cultivation. In all three cultivation scales, comparable cell densities could be achieved regardless of the addition of the booster (Additional file 2: Table S1). However, cultivation in the $250 \mathrm{ml}$ UYF resulted in slightly higher cell densities most likely due to the higher $\mathrm{K}_{\mathrm{L}}$ a values in the larger shake flask [49]. Similarly, increasing the size of the shake flask cultures had no significant negative effect on specific and volumetric $\mathrm{RH}$ yields (Additional file 2: Table S1). Thus, these results demonstrate the good scalability of the RH production process using fed-batch based lactose autoinduction over the shake flask and deepwell plate scales.

\section{Discussion}

Recently, we demonstrated the functionality of the enzyme-based fed-batch like EnPresso system for the heterologous production of hydrogenases in E. coli using the regulatory hydrogenase from $R$. eutropha as a model [48]. With a classical IPTG induction, RH titers of 130$260 \mathrm{mg} \mathrm{L}^{-1}$ could be achieved in shake flask scale. Here, low IPTG concentrations of $50 \mu \mathrm{M}$ favour the solubility of the $\mathrm{RH}$ and the use of the booster increases the specific as well as the volumetric yield [48]. Based on this, in the present work we wanted to evaluate the possibility of enhancing $\mathrm{RH}$ production using autoinduction. Initial experiments in deepwell plates indicated that heterologous RH production in E. coli using autoinduction with lactose is possible (Figs. 1 and 2). The comparison of different lactose amounts used for autoinduction indicated that an intermediate lactose concentration of $2 \mathrm{~g}$ $\mathrm{L}^{-1}$ is optimal for $\mathrm{RH}$ production. Even though $4 \mathrm{~g} \mathrm{~L}^{-1}$ lactose resulted in slightly higher final $\mathrm{OD}_{600}$, the highest specific and even volumetric RH yield was obtained after autoinduction with $2 \mathrm{~g} \mathrm{~L}^{-1}$ lactose (Fig. 2). This is in good accordance with the work of Ali [50] who proposed that low lactose concentrations $\left(0.1-2.0 \mathrm{~g} \mathrm{~L}^{-1}\right)$ would be more profitable for autoinduction in EnPresso B-based fed-batch like cultures, as high lactose concentrations ('2 $\left.\mathrm{g} \mathrm{L}^{-1}\right)$ would lead to a longer batch phase consequently resulting in more biomass but less protein production [50]. Likewise, the faster growth in the presence of high lactose concentrations could lead to oxygen limitation, which further reduces protein synthesis [50]. On the contrary, higher lactose concentrations have been reported to provide an additional benefit for better induction of prolonged protein expression in the autoinduction systems [51, 52]. However, the use of the EnBase fed-batch like system with slow gradual glucose feeding enables slow protein synthesis with slowly growing cells $[53,54]$. Previously, $0.3 \mathrm{~g} \mathrm{~L}^{-1}$ have been calculated as the lowest external lactose concentration sufficient for induction of recombinant protein production in $E$. coli growing at the minimal growth rate, whereas $4.1 \mathrm{~g} \mathrm{~L}^{-1}$ lactose is essential to ensure induction at any growth rate [55]. The sufficiency of relatively low lactose concentrations for successful autoinduction in enzymatic glucose supply systems might be attributed to the constant lactose concentration observed during $24 \mathrm{~h}$ of cultivation [32]. In such systems, the continuous glucose release prevents an diauxic growth shift and consequently lactose consumption while the product is slowly but steadily produced in a correctly folded form [32]. In our case, $2 \mathrm{~g} \mathrm{~L}^{-1}$ lactose seems to be optimal for autoinduction of soluble $\mathrm{RH}$ production in EnPresso B fed-batch like cultured E. coli. Nevertheless, the minimal lactose concentration of $0.5 \mathrm{~g}$ $\mathrm{L}^{-1}$ was enough for induction of recombinant $\mathrm{RH}$ synthesis which is perfectly supported by the result of Mayer et al., who proposed that slow growth might contribute to reduce the need of lactose [32].

Recently, it had been reported that IPTG can replace lactose in the classic lactose-based autoinduction system to enhance protein production in batch cultures [52]. At low IPTG concentrations $(<100 \mu \mathrm{M})$ the inducer is actively transported into the cell by the lactose permease LacY, while at higher IPTG concentrations used for normal induction $(200-1000 \mu \mathrm{M})$ the inducer enters the cell by passive diffusion $[52,56]$. Thus, the expression level is controlled by the IPTG uptake while the excessive inducer remains in the culture medium [57, 58]. Here, our results show that IPTG-based autoinduction is also suitable for heterologous production of $\mathrm{RH}$. Although $10 \mu \mathrm{M}$ IPTG was sufficient for the induction of RH expression, the highest yield was achieved with $50 \mu \mathrm{M}$ IPTG (Fig. 3) which is in clear line with previous studies that only partial induction was achieved at IPTG concentrations below $40 \mu \mathrm{M}$. This is probably due to the fact that either the amount of IPTG is not sufficient to remove all repressor molecules from the operator site 
in the induced cells, or that only a subpopulation could be induced by the limited amount of externally available IPTG. [57, 58]. In our case, $50 \mu \mathrm{M}$ IPTG seems to be enough for full induction of RH expression under control of the bistable lac-derived operon. RH production started already within the first $2 \mathrm{~h}$ of cultivation, indicating the absence of an induction delay which typically occurs in conventional glycerol-based autoinduction medium [12]. Our observations are in clear line with recent findings that protein synthesis occurs under conditions where the glucose concentration drops below $0.3 \mathrm{~g} \mathrm{~L}^{-1}$ in fed-batch like cultures [32]. Thus, we estimate that the initial glucose concentration of $0.5 \mathrm{~g} \mathrm{~L}^{-1}$ seems to be low enough to allow the uptake of IPTG or lactose and consequently inducing $\mathrm{P}_{\text {lac }}$-controlled gene expression in EnPressobased cultures.

When the cultures were scaled up from squared deepwell plates to different UYF scales no significant difference in cell growth was observed. Despite 4 times higher $\mathrm{K}_{\mathrm{L}}$ a values in the $250 \mathrm{ml}$ UYF compared to the deepwell plate [59, 60], similar final cell densities were achieved. This suggests that the availability of oxygen is not a limiting factor which is well supported by previous work showing a reduced sensitivity to the oxygenation level by lactose autoinduction [31]. Our results indicate that the process can be scaled up or down very well. Thus, the fed-batch based lactose autoinduction is suitable for automated high-throughput screenings as a starting point for the development of analogue bioprocesses aimed at the production of difficult to express proteins, e.g. hydrogenases. Additionally, the good scalability of the $\mathrm{RH}$ production process in the current shake flask scales $(125 \mathrm{~mL}$ - and $250 \mathrm{~mL}$-scale) the fed-batch based lactose autoinduction can be applied to rationally designed bioreactor cultivations. Recent studies have shown that the lactose autoinduction concept coupled with an enzymatic glucose release system, compared with glycerol-based systems, is more widely applicable to shaken and stirred bioreactor cultivations with different scales and different aeration capabilities [31,32].

Compared to non-boosted EnPresso B cultures, booster supplementation increased the volumetric $\mathrm{RH}$ production by 2 to 3 -fold, as glucose released from the booster provided an additional carbon source for cell growth and protein production resulting in higher protein yields. The importance of the booster is indicated by higher cell densities as well as higher specific RH yields (Fig. 4C) that could be reached with increasing booster concentrations. However, specific RH production did not significantly increase further when using $2 \times$ booster (Figs. 4 and 6) indicating a crucial limit of the booster effect on the RH production capability of individual cells. Nevertheless, repeated boosting improved both specific and volumetric $\mathrm{RH}$ yield by 1.3 -fold compared to single boosting and even by fourfold compared to non-boosted cultivation, which confirms the positive influence of the booster on RH production and is in good agreement with previous findings [61]. Here, our results highlight the high dependence of $\mathrm{RH}$ production yields on the cell densities under both classic single shot IPTG induction and autoinduction of EnPresso fed-batch like cultures.

A comparison of $\mathrm{RH}$ yields obtained from cultures in UYFs induced with either classical single shot IPTG induction or autoinduction further corroborated the use of autoinduction for hydrogenase production in $E$. coli. While no significant differences in the specific yield could be observed between both IPTG induction protocols, a fourfold increase in volumetric and specific $\mathrm{RH}$ yield was obtained by autoinduction with $2 \mathrm{~g} \mathrm{~L}^{-1}$ lactose compared to optimized single-shot IPTG induction, pointing out an alternative possibility of recombinant protein production in E. coli. Furthermore, the similar volumetric yields together with the shorter cultivation time resulted in a space time yield of nearly $12 \mathrm{mg}(\mathrm{L} \mathrm{h})^{-1}$ with lactose autoinduction in EnPresso B medium which is fourfold higher compared to standard IPTG induction.

Our results presented in this study reconfirm the applicability of such fed-batch lactose autoinduction and the use of IPTG in fed-batch like autoinduction for the production of recombinant proteins in general and of difficult-to-express proteins such as hydrogenases in particular. To date, despite extensive studies on autoinduction systems, all of them using optimized defined media have generally achieved higher final yields of target proteins by increasing final biomass compared to standard IPTG induction [14, 16, 47]. However, our fed-batch autoinduction system ultimately resulted in higher protein yields based on a similar biomass, probably due to an increased or maximized metabolic capacity of individual cell in favor of target protein production. Therefore, this interesting finding renders our developed system potentially advantageous over previous autoinduction systems and of practical implications in terms of improvement of recombinant protein production in the future.

\section{Conclusion}

Here, we combined the autoinduction concept with the fed-batch like enzymatic glucose release technology to improve heterologous regulatory hydrogenase production in E. coli. Taken together, the findings of this study lay a foundation for using this developed approach for efficient production of other similar proteins in future studies of structural and functional characterization as well as biotechnological applications. 


\section{Materials and methods}

\section{Bacterial strain and culture medium}

For all cultivations $E$. coli BQF8RH (BL21-Gold [E. coli B $\mathrm{F}^{-}$ompT hsdS $\left(\mathrm{r}_{\mathrm{B}}{ }^{-} \mathrm{m}_{\mathrm{B}}\right) \mathrm{dcm}^{+}$Tet $^{\mathrm{R}}$ gal endA Hte] harbouring plasmid pQF8) [48], was used. The plasmid allows production of both HoxC and C-terminally strep-tagged HoxB under control of the strong $\mathrm{P}_{\text {lac }}$ derivative $\mathrm{P}_{\text {lac-CTU }}$ [48]. If not stated otherwise all cultivations were carried out in EnPresso B medium according to the manufactures (EnPresso GmbH, Germany) and $25 \mu \mathrm{g} \mathrm{mL}{ }^{-1}$ chloramphenicol were added.

\section{Cultivation in 24-deepwell plates}

Screening of conditions for autoinduction of hox gene expression was performed in square-shaped 24-deepwell plates (24-DWP; Thomson Instrument Company) covered with sterile Breathable Film seal (Starlab, Hamburg, Germany) using EnPresso B with or without addition of booster in a working volume of $3 \mathrm{~mL}$ per well. In both cases $3 \mathrm{U} \mathrm{L}^{-1}$ biocatalyst were used to catalyse glucose release. In deviation from the manufacturer's instructions, the booster was added directly at inoculation. Cultures were inoculated to $\mathrm{OD}_{600}$ of 0.2 and incubated at $30{ }^{\circ} \mathrm{C}$ and $250 \mathrm{rpm}$ with orbital shaking (25 mm offset, Infor HT, Switzerland). Cell density and target protein level were analysed at five time points during the cultivation $(2,6,12,24$ and $30 \mathrm{~h})$. For optimization of the inducer concentration varying concentrations of either IPTG $(0,10,20,50,80$ or $150 \mu \mathrm{M})$ or lactose $(0.5,2$ or $\left.4 \mathrm{~g} \mathrm{~L}^{-1}\right)$ were added at the inoculation time. Additionally, different combinations of glucose $\left(0.5\right.$ or $\left.1 \mathrm{~g} \mathrm{~L}^{-1}\right)$ and lactose $\left(0.5,1\right.$ or $\left.2 \mathrm{~g} \mathrm{~L}^{-1}\right)$ were used for autoinduction in non-boosted cultures.

Improvement of the booster concentration was performed in cultures induced with $50 \mu \mathrm{M}$ IPTG or $2 \mathrm{~g} \mathrm{~L}^{-1}$ lactose. At the time of inoculation, different booster concentrations $(0 \times, 0.25 \times, 0.5 \times, 1 \times, 2 \times)$ were added with $1 \times$ booster corresponding to the manufacturer's recommendation (EnPresso GmbH, Germany). In all cases, glucose release was controlled by addition of $3 \mathrm{U} \mathrm{L}^{-1}$ biocatalyst at inoculation according to the manufacturer's instructions. Cell density and target protein level were analysed after $30 \mathrm{~h}$ of cultivation. Optical densities $\left(\mathrm{OD}_{600}\right)$ of the cultures were determined as described previously [48].

\section{Cultivation in shake-flasks}

Cultivation in the shake-flask scale was carried out in 250-mL Ultra Yield Flasks (UYFs) sealed with a sterile porous membrane seal (AirOtop ${ }^{\mathrm{TM}}$ ) (Thomson Instrument Company) filled with $20 \% \mathrm{v} / \mathrm{v}$ EnPresso B medium with or without booster. For autoinduction, $50 \mu \mathrm{M}$ IPTG or $2 \mathrm{~g} \mathrm{~L}^{-1}$ lactose were added. The shake-flask cultures supplemented with $0.01 \% \mathrm{v} / \mathrm{v}$ antifoam 204 (SigmaAldrich) were inoculated to $\mathrm{OD}_{600}$ of 0.2 and incubated at $30{ }^{\circ} \mathrm{C}$ and $250 \mathrm{rpm}$ ( $25 \mathrm{~mm}$ offset, Infors HT, Switzerland). If required a second dose of booster and biocatalyst were added after $12 \mathrm{~h}$ of induction.

\section{Protein purification and SDS-PAGE analysis}

Cells were harvested by centrifugation for $10 \mathrm{~min}$ at $8000 \times g$ at $4{ }^{\circ} \mathrm{C}$ and pellets frozen at $-20{ }^{\circ} \mathrm{C}$ overnight. After thawing the pellets were resuspended in washing buffer A (100 mM Tris-HCl, pH 8.0, $150 \mathrm{mM} \mathrm{NaCl}$ ) supplemented with $1 \mathrm{mg} \mathrm{mL}^{-1}$ lysozyme and $1 \mathrm{mM}$ PMSF. Here, $4 \mathrm{~mL}$ of washing buffer were used per $1 \mathrm{~g}$ of wet cell weight. Subsequently, cells were disrupted by sonification (30 s on/off, sonotrode with $7 \mathrm{~mm}$ diameter, $60 \%$ amplitude) for 8-10 min. The resulting crude extract was centrifuged for $30 \mathrm{~min}$ at $16,000 \times g$ at $4{ }^{\circ} \mathrm{C}$ to yielding the soluble protein extract. The clarified cell lysates were applied to Strep-Tactin ${ }^{\circledR}$ Gravity Superflow ${ }^{\circledR}$ columns (IBA GmbH, Germany) and processed according to the manufacturer's instructions. For $10 \mathrm{~mL}$ of soluble extract, a $300 \mu \mathrm{L}$ bed volume was used. The column was washed with 6 bed volumes of washing buffer, and the Hox proteins were eluted 6 times with 0.5 bed volume of elution buffer containing $2.5 \mathrm{mM}$ D-desthiobiotin. Subsequently, elution fractions were analysed by SDS-PAGE using $12 \%$ PAA gels. BSA served as a standard for quantification. After staining with colloidal Coomassie solution the gels were scanned and subsequently bands quantified using Image J.

For total protein analysis $0.2 \mathrm{~mL}$ broth samples were collected at the selected time points, centrifuged at $16,000 \times g$ and $4{ }^{\circ} \mathrm{C}$ for $10 \mathrm{~min}$ and pellets stored at $-20^{\circ} \mathrm{C}$. The pellets were resuspended in $2 \times$ SDS sample buffer normalized to an $\mathrm{OD}_{600}$ of 5 and heated for $20 \mathrm{~min}$ at $95{ }^{\circ} \mathrm{C}$. After centrifugation $20 \mu \mathrm{L}$ of the SDS-denatured samples were loaded on $12 \%$ PAA gels as above.

\section{Western blotting}

Western blotting was performed as described recently [48]. Briefly, after SDS-PAGE proteins were transferred onto a PVDF membrane $(0.45 \mu \mathrm{m}$ pore size, Carl Roth, Germany) by semi-dry blotting in a Transblot Turbo Transfer system (Bio-Rad, Germany) at $1.3 \mathrm{~A} / 25 \mathrm{~V}$ for $30 \mathrm{~min}$. Strep-tagged HoxB was detected using monoclonal anti-Strep-tag ${ }^{\circledR}$ II mouse antibody (1:2500 dilution) (iba GmbH, Germany). As a secondary antibody, alkaline phosphatase (AP)-conjugated goat anti-Mouse IgG antibody (Sigma-Aldrich, Germany) was used (1:8000 dilution). Bands were visualized via the AP-catalysed reaction of the chromogenic $\mathrm{BCIP} / \mathrm{NBT}$ substrates as described recently [48]. Blots were digitized with a ScanPrisa 640U and quantified with ImageJ. 


\section{Supplementary Information}

The online version contains supplementary material available at https://doi. org/10.1186/s12934-021-01690-4.

Additional file 1: Figure S1. Cell growth with different amounts of booster in IPTG and lactose autoinduction cultivations

Additional file 2: Table S1. Comparison of cell densities and volumetric $\mathrm{RH}$ production yields obtained from deepwell plate (DWP) to UltraYield flask (UYF) cultures (125 mL or $250 \mathrm{~mL}$ of flask volume) after $24 \mathrm{~h}$ of cultivation using lactose autoinduction.

\section{Acknowledgements}

Not applicable.

\section{Authors' contributions}

QF, MG and PN participated in experiment design and interpretation of the results. QF carried out all laboratory experiments, QF and MG analysed the data. QF drafted the manuscript. MG and PN revised the manuscript. All authors read and approved the final manuscript.

\section{Funding}

Open Access funding enabled and organized by Projekt DEAL.

\section{Availability of data and materials}

All data generated or analysed during this study are included in this published article [and its additional information files].

\section{Declarations}

Ethics approval and consent to participate

Not applicable.

\section{Consent for publication}

Not applicable.

\section{Competing interests}

The authors declare that they have no competing interest.

Received: 25 June 2021 Accepted: 27 September 2021

Published: 18 October 2021

\section{References}

1. Rosano GL, Ceccarelli EA. Recombinant protein expression in Escherichia coli: advances and challenges. Front Microbiol. 2014;5:172.

2. Neubauer P, Wolff C, Hecker M, Hofmann K, Meyer L, Kruschke P, Heinrich $\mathrm{HW}$. Introduction of the tac-promoter by lactose under fermentation conditions. Acta Biotechnol. 1991;11:23-9.

3. Neubauer P, Hofmann K, Holst O, Mattiasson B, Kruschke P. Maximizing the expression of a recombinant gene in Escherichia coli by manipulation of induction time using lactose as inducer. Appl Microbiol Biotechnol. 1992:36:739-44.

4. Neubauer P, Hofmann K. Efficient use of lactose for the lac promoter controlled overexpression of the main antigenic protein of the foot and mouth disease virus in Escherichia coli under fed-batch fermentation conditions. FEMS Microbiol Rev. 1994;14:99-102.

5. Studier FW. Protein production by auto-induction in high density shaking cultures. Protein Expr Purif. 2005;41:207-34.

6. Wu PH, Nair GR, Chu IM. Wu WT High cell density cultivation of Escherichia coli with surface anchored transglucosidase for use as whole-cell biocatalyst for a-arbutin synthesis. J Ind Microbiol Biotechnol. 2008;35:95-101.

7. Görke B, Stülke J. Carbon catabolite repression in bacteria: many ways to make the most out of nutrients. Nat Rev Microbiol. 2008;6:613-24.
8. Fischer D, Teich A, Neubauer P, Hengge-Aronis R. The general stress sigma factor $\sigma(S)$ of Escherichia coli is induced during diauxic shift from glucose to lactose. J Bacteriol. 1998;180:6203-6.

9. Stülke J, Hillen W. Carbon catabolite repression in bacteria. Curr Opin Microbiol. 1999;2:195-201.

10. Kremling A, Bettenbrock K, Laube B, Jahreis K, Lengeler JW, Gilles ED. The organization of metabolic reaction networks. Metab Eng. 2001;3:362-79.

11. Bettenbrock K, Fischer S, Kremling A, Jahreis K, Sauter T, Gilles E-D. A Quantitative approach to catabolite repression in Escherichia coli. J Biol Chem. 2006;281:2578-84

12. Blommel PG, Becker KJ, Duvnjak P, Fox BG. Enhanced bacterial protein expression during auto-Induction obtained by alteration of Lac repressor dosage and medium composition. Biotechnol Prog. 2007;23:585-98.

13. Grabski A, Mehler M, Drott D. Unattended high-density cell growth and and induction of protein expression with the overnight express autoinduction system. Innovations. 2003;17:3-8.

14. Grabski A, Mehler M, Drott D. The overnight express autoinduction system: High-density cell growth and protein expression while you sleep. Nat Methods. 2005;2:233-5.

15. Kunze M, Huber R, Gutjahr C, Müllner S, Büchs J. Predictive tool for recombinant protein production in Escherichia coli shake-flask cultures using an on-line monitoring system. Biotechnol Prog. 2012;28:103-13.

16. Li Z, Kessler W, van den Heuvel J, Rinas U. Simple defined autoinduction medium for high-level recombinant protein production using T7-based Escherichia coli expression systems. Appl Microbiol Biotechnol. 2011;91:1203-13.

17. Gordon E, Horsefield R, Swarts HGP. de Pont JJHHM, Neutze R, Snijder A: Effective high-throughput overproduction of membrane proteins in Escherichia coli. Protein Expr Purif. 2008;62:1-8.

18. Wurm DJ, Hausjell J, Ulonska S, Herwig C, Spadiut O. Mechanistic platform knowledge of concomitant sugar uptake in Escherichia coli BL21(DE3) strains. Sci Rep. 2017;7:45072.

19. Wurm DJ, Herwig C, Spadiut O: How to determine interdependencies of glucose and lactose uptake rates for heterologous protein production with Escherichia coli. In: Methods in Molecular Biology. Humana Press Inc. 2017; Vol. 1586, pp 397-408.

20. Tyler RC, Sreenath HK, Singh S, Aceti DJ, Bingman CA, Markley JL, Fox BG. Auto-induction medium for the production of [U-15N]- and [U-13C U-15N]-labeled proteins for NMR screening and structure determination. Protein Expr Purif. 2005:40:268-78.

21. Fox BG, Blommel PG. Autoinduction of protein expression. Curr Protoc Protein Sci. 2009:56:1-18.

22. Sivashanmugam A, Murray V, Cui C, Zhang Y, Wang J, Li Q. Practical protocols for production of very high yields of recombinant proteins using Escherichia coli. Protein Sci. 2009;18:936-48.

23. Sreenath HK, Bingman CA, Buchan BW, Seder KD, Burns BT, Geetha HV, Jeon WB, Vojtik FC, Aceti DJ, Frederick RO, Phillips GN, Fox BG. Protocols for production of selenomethionine-labeled proteins in $2-L$ polyethylene terephthalate bottles using auto-induction medium. Protein Expr Purif. 2005;40:256-67.

24. Lin ECC. Glycerol Dissimilation and its Regulation in Bacteria. Annu Rev Microbiol. 1976;30:535-78.

25. Kopp J, Slouka C, Ulonska S, Kager J, Fricke J, Spadiut O, Herwig C. Impact of glycerol as carbon source onto specific sugar and inducer uptake rates and inclusion body productivity in Escherichia coli BL21(DE3). Bioengineering. 2017;5:1

26. Soini J, Ukkonen K, Neubauer P. High cell density media for Escherichia coli are generally designed for aerobic cultivations - consequences for large-scale bioprocesses and shake flask cultures. Microb Cell Fact. 2008;7:26.

27. Zimmermann $\mathrm{H}$, Anderlei T, Büchs J. Oxygen limitation is a pitfall during screening for industrial strains. Appl Microbiol Process enignnering. 2006;72:1157-60

28. Hoffman BJ, Broadwater JA, Johnson P, Harper J, Fox BG, Kenealy WR. Lactose fed-batch overexpression of recombinant metalloproteins in Escherichia coli BL21(DE3): Process control yielding high levels of metalincorporated, soluble protein. Protein Expr Purif. 1995;6:646-54.

29. Gombert AK, Kilikian BV. Recombinant gene expression in Escherichia coli cultivation using lactose as inducer. J Biotechnol. 1998;60:47-54.

30. Pei XL, Wang QY, Li CL, Qiu XF, Xie KL, Huang LF, Wang AM, Zeng ZW, Xie T. Efficient production of a thermophilic 2-Deoxyribose-5-Phosphate 
aldolase in glucose-limited fed-batch cultivations of escherichia coli by continuous lactose induction strategy. Appl Biochem Biotechnol. 2011;165:416-25.

31. Ukkonen K, Mayer S, Vasala A, Neubauer P. Use of slow glucose feeding as supporting carbon source in lactose autoinduction medium improves the robustness of protein expression at different aeration conditions. Protein Expr Purif. 2013;91:147-54.

32. Mayer S, Junne S, Ukkonen K, Glazyrina J, Glauche F, Neubauer P, Vasala A. Lactose autoinduction with enzymatic glucose release: characterization of the cultivation system in bioreactor. Protein Expr Purif. 2014;94:67-72.

33. Fontecilla-Camps JC, Volbeda A, Cavazza C, Nicolet Y. Structure/function relationships of [NiFe]- and [FeFe]-hydrogenases. Chem Rev. 2007;1:4273-303.

34. Lubitz W, Ogata H, Ru O, Reijerse E. Hydrogenases. Chem Rev. 2014;1 14:4081-148

35. Vignais PM, Billoud B. Occurrence, classification, and biological function of hydrogenases: an overview. Chem Rev. 2007;107:4206-72.

36. Constant P, Chowdhury SP, Hesse L, Pratscher J, Conrad R. Genome data mining and soil survey for the novel group 5 [NiFe]-hydrogenase to explore the diversity and ecological importance of presumptive highaffinity $\mathrm{H}_{2}$-oxidizing bacteria. Appl Environ Microbiol. 2011;77:6027-35.

37. Lauterbach L, Idris Z, Vincent $K A$, Lenz $O$. Catalytic properties of the isolated diaphorase fragment of the $\mathrm{NAD}^{+}$-reducing [NiFe]-hydrogenase from Ralstonia eutropha. PLoS ONE. 2011;6:25939-51.

38. BurgdorfT, Lenz O, Buhrke T, Van Der Linden E, Jones AK, Albracht SPJ, Friedrich B. [NiFe]-hydrogenases of Ralstonia eutropha H16: Modular enzymes for oxygen-tolerant biological hydrogen oxidation. J Mol Microbiol Biotechnol. 2005;10:181-96.

39. Friedrich B, Fritsch J, Lenz O. Oxygen-tolerant hydrogenases in hydrogenbased technologies. Curr Opin Biotechnol. 2011;22:358-64.

40. Lenz O, Bernhard M, Buhrke T, Schwartz E, Friedrich B. The hydrogensensing apparatus in Ralstonia eutropha. J Mol Microbiol Biotechnol. 2002;4:255-62.

41. Buhrke T, Lenz O, Porthun A, Friedrich B. The $\mathrm{H}_{2}$-sensing complex of Ralstonia eutropha: Interaction between a regulatory [NiFe] hydrogenase and a histidine protein kinase. Mol Microbiol. 2004:51:1677-89.

42. Buhrke T, Lenz O, Krauss N, Friedrich B. Oxygen tolerance of the $\mathrm{H}_{2}$-sensing [NiFe] hydrogenase from Ralstonia eutropha $\mathrm{H} 16$ is based on limited access of oxygen to the active site. J Biol Chem. 2005;280:23791-6.

43. Volbeda A, Charon M-H, Piras C, Hatchikian EC, Frey M, Fontecilla-Camps JC. Crystal structure of the nickel-iron hydrogenase from Desulfovibrio gigas. Nature. 1995;373:580-7.

44. Bernhard M, Buhrke T, Bleijlevens B, De Lacey AL, Fernandez VM, Albracht SPJ, Friedrich B. The $\mathrm{H}_{2}$ Sensor of Ralstonia eutropha. J Biol Chem. 2001:276:15592-7.

45. Buhrke T, Löscher S, Lenz O, Schlodder E, Zebger I, Andersen LK, Hildebrandt P, Meyer-Klaucke W, Dau H, Friedrich B, Haumann M. Reduction of unusual iron-sulfur clusters in the $\mathrm{H}_{2}$-sensing regulatory NiFe hydrogenase from Ralstonia eutropha H16. J Biol Chem. 2005;280:19488-95.

46. Horch M, Schoknecht J, Mroginski MA, Lenz O, Hildebrandt P, Zebger I. Resonance raman spectroscopy on [NiFe] Hydrogenase provides structural insights into catalytic intermediates and reactions. J Am Chem Soc. 2014;136:9870-3.

47. Roncaroli $\mathrm{F}$, Bill E, Lenz O. Cofactor composition and function of a $\mathrm{H}_{2}$ -sensing regulatory hydrogenase as revealed by Mössbauer and EPR spectroscopy. Chem Sci. 2015;6:4495-507.

48. Fan Q, Caserta G, Lorent C, Lenz O, Neubauer P, Gimpel M. Optimization of culture conditions for oxygen-tolerant regulatory [NiFe]-Hydrogenase production from Ralstonia eutropha H16 in Escherichia coli. Microorganisms. 2021;9:1195.

49. Glazyrina J, Materne E, Hillig F, Neubauer P, Junne S. Two-compartment method for determination of the oxygen transfer rate with electrochemical sensors based on sulfite oxidation. Biotechnol J. 2011;6:1003-8.

50. Ali BA: Application of the enzyme controlled glucose feeding for the production of recombinant proteins. Tech Univ Berlin 2018.

51. Studier FW: Stable expression clones and au-toinduction for protein production in Escherichia coli. Structural Genomics; Humana Press: Totowa, NJ, 2014; Vol. 1091.
52. Faust G, Stand A, Weuster-Botz D. IPTG can replace lactose in auto-induction media to enhance protein expression in batch-cultured Escherichia coli. Eng Life Sci. 2015;15:824-9.

53. Panula-Perälä J, Šiurkus J, Vasala A, Wilmanowski R, Casteleijn MG, Neubauer P. Enzyme controlled glucose auto-delivery for high cell density cultivations in microplates and shake flasks. Microb Cell Fact. 2008;7:31.

54. Krause M, Ukkonen K, Haataja T, Ruottinen M, GlumoffT, Neubauer A, Neubauer P, Vasala A. A novel fed-batch based cultivation method provides high cell-density and improves yield of soluble recombinant proteins in shaken cultures. Microb Cell Fact. 2010;9:11.

55. Yildirim N, Mackey MC. Feedback regulation in the lactose operon: A mathematical modeling study and comparison with experimental data. Biophys J. 2003:84:2841-51.

56. Marbach A, Bettenbrock K. Lac operon induction in Escherichia coli: Systematic comparison of IPTG and TMG induction and influence of the transacetylase LacA. J Biotechnol. 2012;157:82-8.

57. Fernández-Castané $A$, Vine $C E$, Caminal G, López-Santín J. Evidencing the role of lactose permease in IPTG uptake by Escherichia coli in fed-batch high cell density cultures. J Biotechnol. 2012;157:391-8.

58. Fernández-Castané A, Caminal G, López-Santín J. Direct measurements of IPTG enable analysis of the induction behavior of Escherichia coli in high cell density cultures. Microb Cell Fact. 2012;11:1-9.

59. Duetz WA, Witholt B. Oxygen transfer by orbital shaking of square vessels and deepwell microtiter plates of various dimensions. Biochem Eng J. 2004;17:181-5

60. Ukkonen K, Vasala A, Ojamo H, Neubauer P. High-yield production of biologically active recombinant protein in shake flask culture by combination of enzyme-based glucose delivery and increased oxygen transfer. Microb Cell Fact. 2011;10:107.

61. Li J, Jaitzig J, Hillig F, Süssmuth R, Neubauer P. Enhanced production of the nonribosomal peptide antibiotic valinomycin in Escherichia coli through small-scale high cell density fed-batch cultivation. Appl Microbiol Biotechnol. 2014;98:591-601.

\section{Publisher's Note}

Springer Nature remains neutral with regard to jurisdictional claims in published maps and institutional affiliations.

Ready to submit your research? Choose BMC and benefit from:

- fast, convenient online submission

- thorough peer review by experienced researchers in your field

- rapid publication on acceptance

- support for research data, including large and complex data types

- gold Open Access which fosters wider collaboration and increased citations

- maximum visibility for your research: over $100 \mathrm{M}$ website views per year

At BMC, research is always in progress.

Learn more biomedcentral.com/submissions 